\title{
Factors Affecting the Uptake of Anti-Malarial Drugs by Children in Public Primary Health Facilities in Cross River State, Nigeria
}

\author{
Emmanuel Ezedinachi ${ }^{*}{ }^{1,2}$, Friday Odey ${ }^{1,2}$, Soter Ameh $^{2}$, Olabisi Oduwole ${ }^{1,2}$, Ekpereonne Esu ${ }^{1,2}$, \\ Regina Ejemot-Nwadiaro ${ }^{1,2}$, Godwin Ntadom ${ }^{3}$, Aniekan Etokidem ${ }^{1,2}$, Ekong Udoh ${ }^{2}$, \\ Vivian Asiegbu ${ }^{1,2}$, Iyam Ugot ${ }^{4}$, Patrick Asuquo ${ }^{5}$, Ambrose Alaribe ${ }^{1,2}$, Joe Charles ${ }^{6}$, \\ Ernest Nwokolo ${ }^{7}$ and Martin Meremikwu ${ }^{1,2}$ \\ ${ }^{I}$ College of Medical Sciences, University of Calabar, Calabar. \\ ${ }^{2}$ Calabar Institute of Tropical Diseases Research \& Prevention, University of Calabar Teaching Hospital, Calabar, \\ Nigeria \\ ${ }^{3}$ National Malaria Control Program, FMOH, Abuja, Nigeria \\ ${ }^{4}$ Roll Back Malaria Programme, Office of the Governor of Cross River State, Nigeria \\ ${ }^{5}$ Academic Planning, University of Calabar, Nigeria \\ ${ }^{6}$ Faculty of Social Sciences, University of Calabar, Nigeria \\ ${ }^{7}$ Society for Family Health, Abuja, Nigeria
}

\begin{abstract}
Background: Despite the supply of artemisinin-based combination therapy (ACT) drugs to public health facilities in Nigeria, the uptake of these drugs appear to have remained suboptimal with low improvement in childhood morbidity and mortality.

Aim: To use a controlled study to estimate the factors affecting the uptake of ACT in public health facilities in Cross River State (CRS), Nigeria.

Methods: The design of this study was cross sectional analytical. The study was carried out in two sites, Akpabuyo (experimental) and Obudu (control) Local Government Areas (LGA) in the south and northern parts of CRS, Nigeria, respectively. Multidisciplinary research team consists of health professionals, biomedical and social scientists who worked with staff of the target facilities. Validated semi-structured questionnaires were administered by trained interviewers on respondents of consecutive households selected by multi-stage sampling procedure.

Results: A total of 1250 households (588 in Akpabuyo and 662 in Obudu LGAs) were assessed. More informants in Obudu had formal education than in Akpabuyo $(\mathrm{p}<0.0001)$. Mortality of U5 children was higher in Akpabuyo. Stepwise regression analysis showed that farmers $(p=0.009)$ and people without formal education $(p=<0.0001)$ were less likely than older age group $(\mathrm{p}=<0.0001)$ to access anti-malaria drugs in Akpabuyo. Religious beliefs $(\mathrm{p}=0.003)$ also predicted uptake of ACTs in Obudu.

Conclusion: Informants' occupation, age, education and religious beliefs were key determinants of uptake of ACTs in public health facilities in Nigeria. We recommend targeted malaria education programmes to explore the belief systems in treating fevers in children in this population.
\end{abstract}

Keywords: Artemisinin-based combined drugs, public primary health facilities, uptake.

\section{INTRODUCTION}

The Roll Back Malaria (RBM) partnership has succeeded in raising global awareness and providing funding for malaria control activities [1]. This became necessary because of the widespread resistance to the once effective antimalarial drugs [2]. The efforts has led to a number of malaria control successes including availability of artemisinin

*Address correspondence to this author at the Directorate of Research, University of Calabar, Calabar, Cross River State, Nigeria;

Tel: +234-703871685; E-mails: eezedinachi@hotmail.com,

uezedinachi@stepbunicaluniport.org combined anti-malarial drugs in public health facilities in several countries including Nigeria [3-7]. Most of the successes have been reported from islands and smaller countries with significant external support [3-6].

However, the malaria disease burden appears to be deteriorating in Nigeria, despite global commitment to fight the disease [8]. Unfortunately, the Economic Empowerment through the Development Strategy of the Federal Government (NEEDS) and State Government (SEEDS) of Nigeria as well as attainment of the Millennium Development Goals (MDGs) may not be feasible without effective malaria control. The 2005-2015 RBM global 
strategic plan has noted that six of the eight MDGs cannot be attained without effective malaria control in place [9]. With the current state of malaria control in Nigeria, the country may neither meet the targets set during the Abuja declaration [10] nor achieve the MDGs that relate directly or indirectly to the disease.

The Global fund and other partners of the Roll Back Malaria (RBM) Initiative supply free or subsidized drugs to various health facilities, but children still die of malaria in their homes without accessing the drugs in the health facilities. The World Bank estimates indicated that in 2009, only $33 \%$ of Nigerian children under-5 years of age with fever had access to anti-malaria drugs [8]. It appears that these anti-malarials are not reaching the target population. This was demonstrated in another study when the response to announcements on availability of free testing and treatment for malaria brought out more ill children who obviously were lying ill at home until the announcements [11]. It is therefore very important to find out whether the efforts of RBM partners and the Federal Government of Nigeria in delivering ACT anti-malarial drugs are reaching the under-5 which is the most vulnerable age group to the severe forms of malaria infection.

The UNICAL community directed malaria project [11], a Science and Technology Education Post Basic (STEP-B) project sponsored by the Federal Government of Nigeria, assisted by the World Bank. The goal of the project is to improve access of under-five children to anti-malarial drugs in public health facilities in Nigeria. The present study is a preliminary assessment of the baseline factors that affect uptake of anti-malarial drugs in the state before administration of the intervention. The aim of this study was to determine the factors that affect the uptake of available ACTs by under five children in public health facilities in Cross River State, Nigeria.

\section{METHODS}

DESIGN: This is a cross sectional study to estimate the factors that may affect access and drug utilization in rural public health facilities. The target population is children under 5 years of age and the parents or child care-givers were the respondents.

SITE: The study was carried out in Cross River State, one of the 36 states in Nigeria. The state is situated in southeastern part of Nigeria. It has a population of over 2.89 million people in 2006 census [12]. The state consist of 18 local government areas (LGAs), grouped into three senatorial districts. There are 10 wards in each of the 18 LGAs. The Cross River State administrative headquarters is Calabar, situated in the southern senatorial district. The study was carried out in two LGAs namely Akpabuyo LGA in the southern senatorial district was the interventional (or experimental) site, while Obudu at the other extreme end of the northern senatorial district was the control LGA. Malaria is holoendemic in the study areas and transmission is throughout the year [13].

ETHICAL CONSIDERATIONS: Ethical approval for this study was obtained from the Ethical Review Committees of the Cross River State Ministry of Health and the University of Calabar Teaching Hospital, Calabar. Community and Traditional leaders of all the communities gave their consent for data collection from their respective communities. Similarly, head of households or their representatives gave verbal consent before the questionnaire was administered on them to collect data for the study.

SAMPLE SIZE ESTIMATION: Using a two proportion sample size formula (approximately equal number in the two arms) with a two-sided distribution, 95\% confidence level, $90 \%$ power, $40 \%$ and $36 \%$ of U5s using anti-malarial drugs in urban and rural locations respectively [14], we calculated a minimum sample size of 535 subjects (including 10\% nonresponse) for each arm of the study.

SAMPLING TECHNIQUES: Multistage sampling was used in this study. In stage 1, the state was divided into 3 senatorial districts based on the existing political structure. The southern and northern senatorial districts were chosen for the study based on their location and to reduce the influence of the intervention on the control site. In stage 2, simple random sampling by balloting was used to select the LGAs in the chosen senatorial districts. Akpabuyo LGA in the southern senatorial district was picked as the interventional (or experimental) site, while Obudu at the other extreme end (about $350 \mathrm{~km}$ from the intervention LGA) of the northern senatorial district served as the control LGA. In the final stage of the sampling, 5 electoral wards in each LGA were picked through balloting (simple random sampling). Each of the electoral wards was considered as a cluster for this study.

STUDY TEAM: The research team was made of scientists from different disciplines led by the health professionals. Other members of the research team were biomedical and social scientists. All the research team members were trained on the methods as stated in the protocol of this study. Emphasis was laid on correct administration and completion of the interviewer administered questionnaire. Two healthcare staff serving in designated public health facilities from each of the 10 electoral wards were also trained and served as local guides for the data collection team in Akpabuyo LGA since it is the intervention site. The same team members that collected data in the intervention LGA were used to collect data in the control LGA (Obudu). Local guides were recruited and trained in the control LGA to guide the team into the community.

DATA COLLECTION: In each clusters, data collection started in the community immediately surrounding the main public primary health facility. Trained interviewers administered the questionnaire on heads of consecutive households (or the next most responsible member of the household in the absence of the head of household). To determine the point where data collection should start from, a bottle was spun at the entrance of the health centre and the team went wherever the mouth of the bottle pointed. Data collection started from the houses immediately surrounding the health facility and continued in consecutive consenting households until the team got to the last house in that community and then returned to the health centre. The process described above was repeated to determine the next direction until 50 households were covered in each of the electoral wards. The number of household surveyed was based on the assumption that there is average of one U5 
child in each household and interviewing 50 households in five electoral wards will give us the minimum sample size.

The same team of supervisors and interviewers collected baseline data in both the intervention and the control LGAs using the same data collection tool. This was to ensure that data collection procedure was consistent in both the intervention and control sites.

INSTRUMENT FOR DATA COLLECTION: The questionnaire was developed specifically for this project, validated and piloted before use. It was prepared in 4 sections. The first section was to collect data on the demographic characteristics of the household (respondent age, relationship to child/children, marital status, education, occupation and religion). Information was also collected on number of under-5 population including mortality among this population. Family income was also estimated. In the second section, prevalence of all cause mortality among under-5 children was assessed. The third section was to assess the main complaints of patients with recent symptoms suggestive of malaria as well as the first and second treatments actions taken by the caregivers to treat the index child with suspected malaria. The last section of the data collection instrument assessed factors that could potentially influence care-seeking practices. Information was also sought from respondents on how to improve utilization of public health facilities.

DATA MANAGEMENT: Questionnaires were checked for completeness and consistency by supervisors at the end of each day after the trained data collectors returned from the field. Data entry was performed by the same trained data entry clerks using Epi-Info 2000 version 3.3.2 statistical software. The process of data entry was supervised by one project co-investigator. A Biostatistician imported the dataset into STATA ${ }^{\mathrm{TM}}$ version 10 statistical software for data analysis. Level of statistical significance was set at $\mathrm{p} \leq 0.05$. Differences between study population variables were determined using independent t-test and chi square test. Maximum likelihood estimation of odds ratio was used to fit the logistic regression model. Beginning with an empty model, the stepwise method was use to select predictors of uptake of antimalarial drugs in the public health facilities. The assumptions of the logistic regression were met in the construction of the parsimonious model for this study. These included: the true conditional probabilities are a logistic function of the independent variables; no extraneous variables were included; no important variables were omitted; the observations were independent of one another; and the independent variables were not linear combinations of each other.

\section{RESULTS}

A total of one thousand, two hundred and fifty (1250) households were assessed for both local government areas (LGAs). Five hundred and eighty-eight (588) households were surveyed in Akpabuyo LGA while 662 households were surveyed in Obudu LGA.

The socio-demographic characteristics of respondents in both LGAs are shown in Table $\mathbf{1}$. The table shows that there were statistically significant differences between the two LGAs in formal education (fisher's exact test; $p<0.0001$ ), occupation (fisher's exact test; $\mathrm{p}<0.0001$ ), informant relationship $\left(X^{2}\right.$ test $\left.=275.4 ; \mathrm{p}<0.0001\right)$ and marital status of informant (fisher's exact test; $p<0.041$ ).

Table 2 shows that there was no statistically significant difference in the knowledge of fever as the cardinal symptom of malaria among informants in the two local government areas in the study settings $(p=0.285)$. The table also shows that the All-cause U5 mortality rate was higher in Akpabuyo LGA (481/1000 live births/year) than in Obudu LGA (276/1000 live births/year) and this difference was statistically significant $(\mathrm{p}<0.0001)$.

Table 3 shows the result of the stepwise logistic regression analysis to determine variables that significantly predicted uptake of anti-malarial drugs in public health facilities in the two LGAs. In Akpabuyo LGA, informants who were farmers $(\mathrm{OR}=0.42(0.22 ; 0.80) \mathrm{p}=0.009)$ and informants with no formal education $(\mathrm{OR}=0.20(0.09 ; 0.48) \mathrm{p}=<0.0001)$ or primary education (marginally significant at $\mathrm{p}=0.05$ ) were less likely to use anti-malarial drugs in public health facilities. On the other hand, informants were more likely $(\mathrm{OR}=8.31$ (3.04 ; 22.74) $\mathrm{p}=<0.0001)$ to use ACTs in the public health facilities with increasing age starting from 25 years to a peak of 54 years. In Obudu LGA, informants who were apprentices were more likely $(\mathrm{OR}=23.73(10.61 ; 50.71) \mathrm{p}<0.0001)$ to use antimalarial drugs in public health facilities. On the other hand, informants with religious belief about taking drugs were $85 \%$ less likely $(\mathrm{OR}=0.32(0.15 ; 0.67) \mathrm{p}=0.003)$ to use antimalarial drugs in public health facilities.

\section{DISCUSSION}

Good understanding of a community's perception of health issues should guide planning and implementation of disease control programs and efficient utilization of the available services. An earlier study by in this environment on the perception of malaria had shown that members of the community recognize the symptoms associated with malaria disease [15]. This fact has been re-confirmed in this study as in both LGAs, the respondents recognized fever as the cardinal symptom of malaria. Having established that the features of malaria are well known, it is important to ensure that there is access to the effective treatment. Delay in accessing treatment for malaria in under- 5 children can be fatal. A study in West Bengal [16] showed that delay of more than 48 hours from the onset of symptoms to the administration of effective treatment is a determinant of fatality. The Roll Back Malaria (RBM) initiative recommends that treatment for malaria should commence within 24 hours of onset of symptoms [17].

It is known that increased income has a positive effect on the utilization of modern healthcare services. Differential utilization of health services by different occupation groups also suggests occupation as one of the possible factors. The findings of the present study are therefore in keeping with earlier reports that occupation is an important factor in assessing effective anti-malarial therapy. The occupation of the respondents relate directly with their earning ability. In a study of barriers to prompt and effective treatment among poor people, reported that $40 \%$ of individuals who bought drugs from patent medicine vendors did not have enough money to pay for their treatment [18]. On the other hand, most households with higher regular income were more likely to purchase and use the correct dosage of drugs [19]. 
Table 1. Socio-Demographic Characteristics of Respondents in Both LGAs

\begin{tabular}{|c|c|c|c|c|}
\hline Variable & Akpabuyo n (\%) & Obudu n (\%) & Test Statistic & p-Value \\
\hline $\begin{array}{l}\text { Education } \\
\text { No formal } \\
\text { Primary } \\
\text { Secondary } \\
\text { Tertiary } \\
\text { Others }\end{array}$ & $\begin{array}{c}249(43.1) \\
152(26.3) \\
155(26.8) \\
21(3.6) \\
1(0.2)\end{array}$ & $\begin{array}{c}59(9.0) \\
339(51.7) \\
167(25.4) \\
85(13.0) \\
6(0.9)\end{array}$ & Fisher's exact test & $<0.0001$ \\
\hline $\begin{array}{l}\text { Occupation } \\
\text { Apprentice } \\
\text { Civil servant } \\
\text { Farming } \\
\text { Fishing } \\
\text { Trading } \\
\text { Others }\end{array}$ & $\begin{array}{c}24(4.2) \\
36(6.2) \\
287(49.6) \\
2(0.3) \\
160(27.6) \\
70(12.1)\end{array}$ & $\begin{array}{l}280(42.9) \\
57(8.7) \\
136(20.9) \\
2(0.3) \\
102(15.6) \\
75(11.6)\end{array}$ & Fisher's exact test & $<0.0001$ \\
\hline $\begin{array}{l}\text { Religion } \\
\text { Christianity } \\
\text { Islam }\end{array}$ & $\begin{array}{c}584(100.0) \\
0(0.0)\end{array}$ & $\begin{array}{c}660(99.8) \\
1(0.2)\end{array}$ & Fisher's exact test & 1.000 \\
\hline $\begin{array}{l}\text { Mean income (Naira) } \\
\text { Husband } \\
\text { Wife } \\
\text { Children } \\
\text { Others }\end{array}$ & $\begin{array}{c}12,871 \\
6,456 \\
- \\
14,333\end{array}$ & $\begin{array}{c}11,549 \\
5,854 \\
- \\
16,632\end{array}$ & $\begin{aligned} \text { t-test } & =1.369 \\
\text { t-test } & =0.641 \\
& - \\
\text { t-test } & =-0.310\end{aligned}$ & $\begin{array}{c}0.171 \\
0.522 \\
- \\
0.769\end{array}$ \\
\hline $\begin{array}{l}\text { Informant relationship } \\
\text { Brother } \\
\text { Father } \\
\text { Mother } \\
\text { Relatives } \\
\text { Sister }\end{array}$ & $\begin{array}{c}8(1.4) \\
103(17.5) \\
251(42.7 \\
213(36.2) \\
13(2.2)\end{array}$ & $\begin{array}{c}19(2.9) \\
77(11.7) \\
536(81.1) \\
17(2.6) \\
11(1.7)\end{array}$ & $X^{2}$ test $=275.4$ & $<0.0001$ \\
\hline $\begin{array}{l}\text { Age of informant } \\
15-24 \\
25-34 \\
34-44 \\
45-54 \\
55-64 \\
65+ \\
<15\end{array}$ & $\begin{array}{c}310(52.8) \\
143(24.4) \\
97(16.5) \\
24(4.2) \\
5(0.8) \\
3(0.5) \\
5(0.8)\end{array}$ & $\begin{array}{c}345(52.3) \\
175(26.5) \\
103(15.6) \\
22(3.3) \\
3(0.5 \\
6(0.9) \\
6(0.9)\end{array}$ & Fisher's exact test & 0.856 \\
\hline $\begin{array}{l}\text { Marital status of informants } \\
\text { Divorced } \\
\text { married } \\
\text { separated } \\
\text { single } \\
\text { widowed }\end{array}$ & $\begin{array}{c}6(1.0) \\
465(79.9) \\
36(6.2) \\
56(9.6) \\
19(3.3)\end{array}$ & $\begin{array}{c}4(0.6) \\
570(86.4) \\
24(3.6) \\
47(7.1) \\
15(2.3)\end{array}$ & Fisher's exact test & 0.041 \\
\hline
\end{tabular}

The present study shows that the older respondents were more likely to access care in a formal health setting. The reason for this observation is not immediately obvious from the study but may be related to maturity of the respondent. The older respondents are more likely to be earning money and can also take mature decisions with regards to where to assess healthcare. It is also possible that the older female caregiver started bearing children later due to time spent acquiring education. It has been shown that those with higher education tend to choose to be attended by healthcare providers rather than indulge in self treatment [20]. It is well recognized that maternal education has a positive impact on the utilization of healthcare services [21, 22]. It has been shown that mothers with Primary level education are more likely to use health facilities than those without any education [22], and is in keeping with the findings of the present study. Maternal education increases their ability to positively assess the sick children and utilization of the available of healthcare services. It also empowers women to use available information more effectively to maintain or achieve good health status both for themselves and their children by seeking proper medical care. In a review of 
Table 2. Knowledge of Fever as Cardinal Symptom of Malaria and All-Cause Mortality of Children in Both Study Sites (Experimental and Control)

\begin{tabular}{|l|c|c|c|}
\hline \multicolumn{1}{|c|}{ Variable } & Akpabuyo $(\mathbf{n}=\mathbf{5 5 8})$ & Obudu (n= 662) & Difference in Proportion \\
\hline \hline Fever is cardinal symptom of malaria & $571(97.1 \%)$ & $649(98.0 \%)$ & \multirow{2}{*}{$X^{2}=1.143 ; \mathrm{p}=0.285$} \\
\cline { 1 - 3 } Fever is not cardinal symptom of malaria & $17(2.9 \%)$ & $13(2.0 \%)$ & \multirow{2}{*}{$0.205(0.163 ; 0.248) ; \mathrm{p}<0.0001$} \\
\hline
\end{tabular}

Table 3. Factors Associated with Uptake of Anti-Malarial Drugs in the Study Settings

\begin{tabular}{|c|c|c|}
\hline \multirow{2}{*}{ Variable } & \multicolumn{2}{|c|}{ Stepwise Logistic Regression of Uptake of Anti-Malarial Drugs } \\
\hline & $\begin{array}{l}\text { Akpabuyo LGA }(\mathrm{n}=543 *) \\
\text { OR }(95 \% \text { CI) p-Value }\end{array}$ & $\begin{array}{l}\text { Obudu LGA }(n=639 *) \\
\text { OR }(95 \% \text { CI }) \text { p-Value }\end{array}$ \\
\hline \multicolumn{3}{|l|}{$\begin{array}{l}\text { Occupation } \\
\end{array}$} \\
\hline Farming & $0.42(0.22 ; 0.80) \mathrm{p}=0.009$ & Not significant \\
\hline Apprentice & Not significant & $23.20(10.61 ; 50.71) \mathrm{p}=<0.0001$ \\
\hline \multicolumn{3}{|l|}{ Education } \\
\hline No formal & $0.20(0.09 ; 0.48) \mathrm{p}=<0.0001$ & Not significant \\
\hline Primary & $0.57(0.32 ; 0.99) \mathrm{p}=0.05$ & Not significant \\
\hline \multicolumn{3}{|l|}{ Age of informant (yr) } \\
\hline $25-34$ & $1.88(1.02 ; 3.30) \mathrm{p}=0.05$ & Not significant \\
\hline $35-44$ & $2.87(1.48 ; 5.60) \mathrm{p}=0.002$ & Not significant \\
\hline $45-54$ & $8.31(3.04 ; 22.74) \mathrm{p}=<0.0001$ & Not significant \\
\hline Religious belief about taking drugs & Not significant & $0.32(0.15 ; 0.67) p=0.003$ \\
\hline
\end{tabular}

* Observations were $<588$ and $<662$ in Akpabuyo and Obudu LGAs respectively because of list wise deletion of cases with missing values on any variable used in the analysis.

poverty and health sector inequalities showed that a combination of factors such as education, income, health specific knowledge, accessibility of health services are all important in accessing health services in developing countries [23].

It has been shown that choice of where to obtain healthcare depends on a combination of factors. Common reasons for choosing where to seek medical treatment include distance to source of health care, availability of free/cheap treatment, availability of drugs, and quick attention to patients in the health-care facility [24]. They also argued that the major reasons mentioned for choosing where health care is sought was distance to source of health care, free and cheap treatment [24]. The major drawback to promptly access artemisinin combined therapy was the limited availability of the subsidized drugs in places where most caretakers sort help [25]. Thus the decision of where to seek healthcare depends on many factors.

We therefore conclude that factors such as occupation, education, older age and religious beliefs are key determinants of uptake of ACTs in public primary health settings in Cross River State. We recommend that the current poverty alleviation efforts of the present administration be sustained in order to improve access to not only anti-malarial drug but better healthcare for the entire population.

\section{ACKNOWLEDGEMENTS}

This study is one of the projects sponsored by the Science and Technology Education Post-Basic (STEP-B) of Nigeria, assisted by the World Bank.

We appreciate the technical support of National Director of the National Malaria Control Program, Federal Ministry of Health and State Ministry of Health (Special Adviser on RBM) for their participation. World Health Organization office in Calabar offered useful advice technical support in planning and implementation. The Society for Family Health (SFH) and Africare both supplied some of the rapid diagnostic kit tests to public health facilities in Akpabuyo LGA where the work was done. We also thank the Chairman and staff of both LGAs as well as the Council of Chiefs and the participants for their co-operation and support.

\section{CONFLICT OF INTEREST}

The authors have declared that no conflict of interests exists.

\section{REFERENCES}

[1] RBM_WHO: The Global Malaria Action Plan. Roll Back Malaria Partnership. World Health Organization. 2008. Available from: http:// www.rollbackmalaria.org/gmap/gmap.pdf. [Accessed 1 November 2011].

[2] Ezedinachi EN, Ekanem OJ, Chukwuani CM, et al. Efficacy and tolerability of a low-dose mefloquine-sulfadoxine-pyrimethamine combination compared with chloroquine in the treatment of acute malaria infection in a population with multiple drug-resistant Plasmodium falciparum. Am J Trop Med Hyg 1999; 61: 114-9. 
[3] Bhattarai A, Ali AS, Kachur SP, et al. Impact of artemisinin-based combination therapy and insecticide treated nets on malaria burden in Zanzibar. PLoS Med 2007; 4: e309.

[4] Ceesay SJ, Casals-Pascual C, Erskine J, et al. Changes in malaria indices between 1999 and 2007 in The Gambia: a retrospective analysis. Lancet 2008; 372: 1545-54.

[5] Chambers RG, Gupta RK, Ghebreyesus TA. Responding to the challenge to end malaria deaths in Africa. Lancet 2008; 371: 1399-1401

[6] Sievers AC, Lewey J, Musafiri P, et al. Reduced paediatric hospitalizations for malaria and febrile illness patterns following implementation of community-based malaria control programme in rural Rwanda. Malaria J 2008; 7:167. Available from: http://www.malariajournal.com/content/ 7/1/167. [Accessed 1 November 2011]

[7] National Policy on Malaria Diagnosis and Treatment. Federal Ministry of Health, National Malaria and Vector Control Division, Abuja Nigeria 2010.

[8] The World Bank Group 2010. World development indicators database. Millennium Developments Goals for Nigeria. Available from: http: //ddp-ext.worldbank.org/ext/ddpreports/ViewSharedReport. [Accessed 01 November 2011].

[9] Global Strategic Partnership for Roll Back Malaria 2005-2015. Available from: http://www.rollbackmalaria.org/forumV/docs/gsp_en. pdf [Accessed 12 November 2011]

[10] WHO: The Abuja Declaration and the Plan of Action. WHO/ CDS/RBM/2003.46. 2003 Available from: http://www.rollbackmalaria. org/docs/abuja_declaration.pdf. [Accessed 13 November 2011]

[11] UNICAL Community-directed malaria project (CDMP). A Proposal approved by the Technical Review Committee of the Science and Technology Education Post-Basic (STEP B) and sponsored by the Science and Technology Education Post-Basic (STEP B) assisted by the World Bank. 2009.

[12] National population census report, Abuja, Nigeria. 2006.

[13] Nigeria Strategic plan 2009-2013. Federal Ministry of Health. National Malaria Control Programme, Abuja, Nigeria. Available from: http://nmcpnigeria.org/f/strategicplan2009-2013. [Accessed 13 October 2011]

[14] Overview of malaria control activities and programme progress. Roll Back Malaria monitoring and Evaluation. Country profile, Nigeria. 2005. Available from: http://www.rollbackmalaria.org/wmr2005/prof iles/nigeria.pdf [Accessed 13 September 2011].
[15] Ezedinachi EN, Egwu IN, Nwangwa MA, Charles JO. Perception of malaria infection in two rural communities in Nigeria. Int Q Community Health Educ 1996; 16: 257-70.

[16] Sarkar J, Murhekar MV, Shah NK, van Hutin Y. Risk factors for malaria deaths in Jalpaiguri district, West Bengal, India: evidence for further action. Malaria J 2009; 8: 133. Available from: http://www. malariajournal.com/content/8/1/133. [Accessed 17 November 2011]

[17] World Health Organization: Roll Back Malaria. The global malaria action plan WHO, Geneva; 2008 Available from: http://www.rollback malaria.org/gmap. [Accessed 20 October 2011]

[18] Chuma J, Okungu V, Molyneux C. Barriers to prompt and effective malaria treatment among the poorest population in Kenya. Malaria $\mathrm{J}$ 2010; 9: 144. Available from: http://www.malariajournal.com/conte nt/9/1/144. [Accessed 3 September 2011]

[19] Watsierah CA, Jura WGZO, Oyugi H, Abong'o B, Ouma C. Factors determining anti-malarial drug use in a peri-urban population from malaria holoendemic region of western Kenya. Malaria J 2010; 9: 295. Available from: http://www.malariajournal.com/content/9/1/295. [Accessed 12 September 2011]

[20] Thuan NTB, Lofgren C, Lindholm L, Chuc NTK. Choice of healthcare provider following reform in Vietnam. BMC Health Serv Res 2008; 8: 162. Available from: http://www.biomedcentral.com/1472-6963/8/162. [Accessed 17 November 2011]

[21] Hjortsberg C. Why do the sick not utilise health care? The case of Zambia. Health Econ 2003; 12: 755-70

[22] Rutstein SO. Factors associated with trends in infant and child mortality in developing countries during the 1990s. Bull World Health Organ 2000; 78: 1256-70.

[23] Wagstaff A. Poverty and health sector inequalities. Bull World Health Organ 2002; 80: 97-105.

[24] Amuge B, Wabwire-Mangen F, Puta C, et al. Health-seeking behavior for malaria among child and adult headed households in Rakai district, Uganda. African Health Sci 2004; 4: 119-24

[25] Simba DO, Warsame M, Kakoko D, et al. Who Gets Prompt Access to Artemisinin-Based Combination Therapy? A Prospective CommunityBased Study in Children from Rural Kilosa, Tanzania. PLoS One 2010; 5: e12104. Available from: http://www.plosone.org doi:10.1371/jour nal.pone.0012104. [Accessed 17 November 2011]

(C) Ezedinachi et al.; Licensee Bentham Open.

This is an open access article licensed under the terms of the Creative Commons Attribution Non-Commercial License (http://creativecommons.org/licenses/by$\mathrm{nc} / 3.0 /$ ) which permits unrestricted, non-commercial use, distribution and reproduction in any medium, provided the work is properly cited. 